Chapter 9

\title{
Use of Natural Products for Direct Anti-Atherosclerotic Therapy
}

\author{
Alexander N. Orekhov, Igor A. Sobenin, \\ Alexandra A. Melnichenko, \\ Veronika A. Myasoedova and Yuri V. Bobryshev
}

Additional information is available at the end of the chapter

http://dx.doi.org/10.5772/52967

\section{Introduction}

Atherosclerosis and vascular disorders, which result from atherosclerosis, represent one of the major problems in the modern medicine and public health. Atherosclerosis is characterized by structural and functional changes of large arteries. The approaches for the treatment of atherosclerosis require at least the prevention of growth of atherosclerotic lesions and reduction in the lipid core mass, which would followed by plaque stabilization. Taken together, these approaches could theoretically result in the regression of arterial lesions.

Atherosclerosis develops in the arterial wall and remains asymptomatic until ischemia of distal organs is evident. Therapy of clinical manifestations of atherosclerosis is largely aimed at reducing symptoms or affecting hemodynamic response and often does not affect the cause or course of disease, namely the atherosclerotic lesion itself. Of course, anti-atherosclerotic effects of statins revealed in many prospective clinical trials may be considered; however, statins have never been recognized as the drugs indicated just for direct treatment or prevention of atherosclerosis. They are used predominately in the course of hypolipidemic therapy, and the effects of treatment are estimated by success in reaching the target level of low density lipoprotein (LDL) cholesterol, but not the regression of atherosclerotic lesion or intimamedia thickness. The last should be considered as beneficial effect, which is mainly due to pleiotropic mechanisms of action. Atherosclerosis develops over many years, so anti-atherosclerotic therapy should be a long-term or even lifelong therapy. Tachyphylaxis, long-term toxicity and cost amongst other issues may present problems for the use of conventional medications in a long-term. Drugs based on natural products can be a good alternative. 
In epidemiological studies of hypercholesterolemia, a high level of plasma cholesterol and the plasma concentration of LDL are significantly associated with the development of premature atherosclerosis [1]. Cholesterol accumulation in the arterial wall is the main sign of atherosclerosis. It was suggested that LDL is the major source of cholesterol deposited in the vessel wall.

Accumulation of cholesterol and other lipids is the most prominent manifestation of atherosclerosis at the arterial cell level. In addition to lipid accumulation, elevated proliferative activity of vascular cells and enhanced synthesis of the extracellular matrix are characteristics of cellular atherogenesis. Collagen and glycoproteins are the main components of the extracellular matrix which forms a fibrous plaque.

Intracellular lipid accumulation can be induced by LDL; however native lipoprotein does not increase the cholesterol content of the cell [2]. On the other hand, incubation of cell culture with chemically modified LDLs results in a massive accumulation of cholesterol in the cells [2]. The in vitro studies revealed a great number of atherogenic modifications of LDL, i.e. modifications which lead to cellular lipidosis [2]. This findings suggest that modified, but not native LDLs are the source of lipids accumulated in arterial cells. Arterial intimal cells populating atherosclerotic lesion are overloaded with lipids, their cytoplasm is almost completely filled with lipid inclusions [3]. These cells are referred to as foam cells.

\section{Cellular Mechanisms of Atherosclerosis}

Recent studies of the cellular mechanisms of atherosclerosis carried out on cultured human aortic cells have revealed the outlined below regularities.

Modified LDL circulates in the bloodstream. We have discovered modified (desialylated) LDL in blood plasma of patients with coronary atherosclerosis [4-7]. This LDL induces accumulation of cholesterol in arterial cells [4-7]. Naturally occurring modified LDL has lesser sialic acid, triglyceride and cholesterol contents, lesser particle size, greater density and negative charge, higher aggregative activity and some other specific features [8]. We have discovered an enzyme, trans-sialydase, responsible for desialylation of LDL particle in blood [9].

In addition to desialylated LDL, more electronegative LDL and small dense LDL were detected in human blood [10,11]. We have performed a comparative study of in vivo modified LDLs. This study showed that more electronegative LDL isolated by ion-exchange chromatography is desialylated LDL [12]. Desialylated LDL isolated from patient blood [4-7] is more electronegative LDL. These facts suggest that both desialylated LDL and electronegative LDL are similar if not identical.

We have found that a particle of desialylated LDL is smaller and denser than that of native LDL, i.e., this LDL is small dense lipoprotein. On the other hand, La Belle and Krauss showed that small dense LDL has a low content of sialic acid, i.e., is desialylated [13]. These findings point out to a similarity between the two types of modified LDL. 
Glycosylation is another type of in vivo LDL modification. Glycosylated LDL was found in the blood of patients with diabetes mellitus [14]. This LDL is also atherogenic, i.e. induces intracellular lipid accumulation [15]. Oxidation is probably also one type of an atherogenic modification of LDL in vivo. There are indirect evidences of the presence of oxidized LDL in vivo [16].

Autoantibodies are produced in response to the appearance of modified LDL (either desialylated, glycosylated or oxidized) in the bloodstream [16-18]. Autoantibodies to desialylated LDL react with both modified and, though with a lesser affinity, native lipoproteins $[17,19,20]$. The interaction between anti-LDL autoantibodies and the lipoprotein results in the formation of LDL-containing immune complexes [12]. Desialylated LDL which enter the cells as a component of immune complexes possess a higher atherogenic potential compared with free lipoprotein, i.e. induce a more intense cholesterol accumulation in the cell [21,22]. The interaction with anti-LDL converts native non-atherogenic LDL into atherogenic, i.e. enables it to induce intracellular cholesterol accumulation which accompanied by enhanced cell proliferation and the extracellular matrix production $[17,20]$. We have found circulating immune complexes consisting of LDL and anti-LDL autoantibodies in the blood of most atherosclerotic patients [21,22]. A positive correlation between level of LDL-containing immune complexes and the severity of atherosclerosis has been demonstrated [23-25].

We and others have demonstrated that LDL is able to form complexes with cellular debris, collagen, elastin, and proteoglycans of human aortic intima [26-28]. Addition of these complexes to cultured cells stimulated intracellular accumulation of lipids. Experiments with iodinated LDL showed an increased uptake and decreased intracellular degradation of lipoproteins in complexes.

In 1989 we showed that in vivo and in vitro modified LDLs are spontaneously self-associated under cell culture conditions, while native LDLs do not forms self-associates [29]. A positive correlation between atherogenic activity of modified LDLs and the degree of LDL selfassociation has been established [30,31]. Lipoprotein associates isolated by gel filtration induced a dramatic increase in the lipid accumulation by cultured human aortic intimal cells. Removal of LDL associates from the incubation medium by filtration through filter with pore diameter $0.1 \mu \mathrm{m}$ completely prevented intracellular lipid accumulation. Thus, self-association increases atherogenic potential of LDL.

Thus, we can conclude that formation of large complexes (self-associates, immune complexes, and complexes with connective tissue matrix) by modified LDL leads to intracellular lipid accumulation through enhanced cellular uptake and slow intracellular degradation of lipoprotein particles.

\section{Anti-Atherogenic and Anti-Atherosclerotic Drugs}

Taken together, our data allow us to identify possible targets for anti-atherosclerotic therapy. The first target is atherogenic modification (desialylation) of LDL particle in blood. Pre- 
vention of LDL modification may be an approach to anti-atherosclerosis therapy. The second approach may be selective removal of modified LDLs from blood (target 2). The third one may be based on prevention of modified LDL accumulation in arterial cells (target 3). Also one more approach is removal of excess lipids from foam cells (target 4). Figure 1 schematically represents these four approaches. We have used all of these approaches and now we believe that the most suitable approach is the third one, namely, the prevention of modified LDL accumulation in arterial cells. Bellow we describe the application of this approach for the development of anti-atherosclerotic therapy.

Agents capable of preventing atherogenesis are anti-atherogenic drugs, agents promoting the regression of atherosclerotic manifestations are anti-atherosclerotic drugs. Prevention of intracellular lipid accumulation accompanied by the stimulation of arterial cell proliferation and massive extracellular matrix production may be regarded as anti-atherogenic (preventive). In terms of arterial cells, any drug effect which does not prevent directly the conversion of the normal cell into an atherosclerotic one (foam cell) should be regarded as an indirect anti-atherogenic action. Only that drug which exhibits its preventive activity at the arterial level is a direct anti-atherogenic drug. At the arterial cell level, a drug with a direct anti-atherosclerotic action should induce the regression of the major cellular manifestations of atherosclerosis, i.e. reduce the intracellular lipid content, suppress cell proliferation and inhibit the extracellular matrix production.

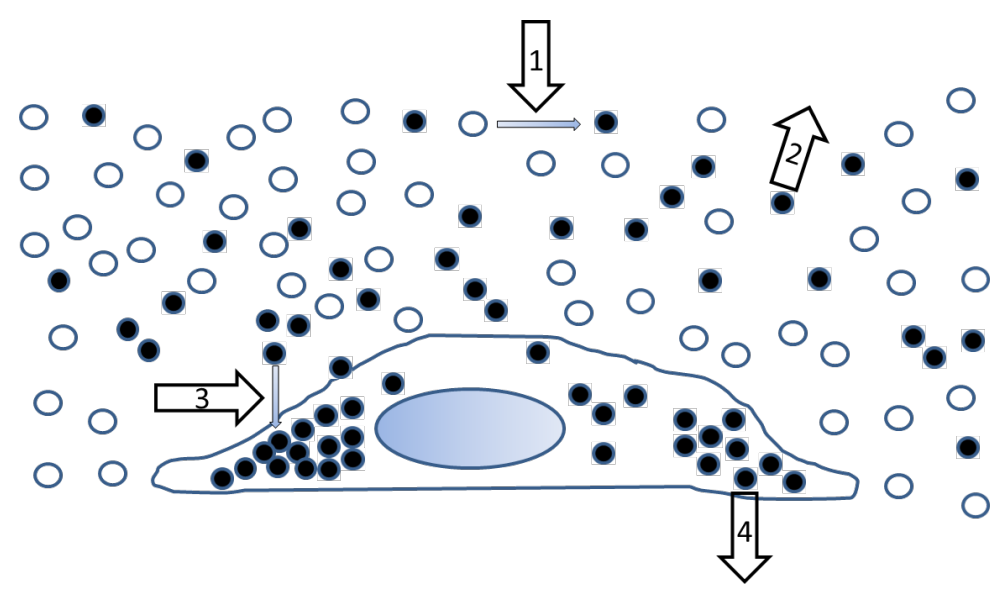

Figure 1. Targets of anti-atherosclerotic and anti-atherogenic drug actions

Solid circles, multiple modified LDL; open circles, native LDL

(see explanation in the text).

Thus, the drugs that affect atherosclerosis can be divided into 3 groups:

- anti-atherosclerotic; 
- direct anti-atherogenic;

- indirect anti-atherogenic.

\section{Cell Model}

The identification of anti-atherosclerotic or/and anti-atherogenic activities of a drug is associated with considerable difficulties. There are no simple and rapid techniques to estimate the anti-atherogenic/anti-atherosclerotic effect of a drug in an animal model or in clinical trials. That is why we employ a culture of human atherosclerotic vascular cells in the screening of potential drugs, investigation of their mechanisms of action and optimization of anti-atherosclerotic drug therapy.

We use human aortic cells to examine the effects of various agents on atherosclerosis-related features of cultured cells. Cells are isolated from the subendothelial part of the human aortic intima, i.e. from the part of aorta which is localized between the endothelial lining and the media [32]. The intima of adult human aorta is a well-defined structure. The thickness of a normal intima varies from 50 to $120 \mu \mathrm{m}$ [32]. Sometimes a thickened intima is called a diffuse intimal thickening [32]. This term underlines its essential difference from a very thin intima of animal and adolescent aorta. Unaffected intima of adult human aorta contains 10-12 lines of subendothelial cells [32].

Using collagenase and elastase, cells are isolated from the subendothelial layer of the intima of both normal and atherosclerotic parts of the aorta [33-36]. This approach makes it possible to study a direct anti-atherosclerotic and anti-atherogenic action of a drug at the vascular cell level. An important advantage of this technique is that human material is used and thus, the results obtained are relevant to human atherosclerosis.

By the well-established criteria, the cells cultured from the intima can be classified as the cells of smooth muscle origin. These cells are stained with antibodies to smooth muscle myosin [33-35]. For further identification of cultured cells we have used a monoclonal antibody HHF-35 which reacts specifically with muscle $\alpha$-actin and can reveal smooth muscle cells [37]. According to our calculations, primary culture of subendothelial cells contains about $90 \%$ of smooth muscle cells interacting with HHF-35. In addition, cells cultured from subendothelial part of uninvolved (healthy) intima have the ultrastructural features characteristic of smooth muscle cells, namely: the basal membrane and filament bundles with dense bodies [33-36]. The culture on which our experiments are performed is represented by mixed population of typical and modified smooth muscle cells revealed in the human aorta earlier [32].

Cells of the subendothelial intima isolated from atherosclerotic lesions retain in primary culture all major characteristics of atherosclerotic cells. Cells cultures from fatty streak and fatty infiltration zones have an enhanced proliferative activity [38]. These cells have a higher proliferative activity as compared with the cells cultured from unaffected intima [38,39].

Many cells cultured from atherosclerotic lesions are so called foam cell containing numerous inclusions filling the whole of the cytoplasm, these inclusions are lipid droplets [34]. The 
bulk of excess lipids in foam cells is represented by free cholesterol and cholesteryl esters [34]. It should be noted that the content and composition of lipids in cultured cells within the first 10-12 days in culture remain unchanged and correspond to the respective indices of freshly isolated cells [34-39].

Cells cultured from the subendothelial intima are capable of synthesizing collagen, proteoglycans and other components of extracellular matrix [40,41].

Thus, the cells isolated from an atherosclerotic lesion of human aorta retain in culture all the main properties characteristic of atherosclerotic cells. They exhibit an enhanced proliferative activity, contain excess cholesterol in the form of intracellular inclusions and synthesize the extracellular matrix. This allows one to regard a culture of atherosclerotic cells as a convenient model for the investigation of the effects of various agents on atherosclerotic manifestations [21]. Thus, the investigations in the cell culture model are carried out directly on exactly the same cells which require a therapeutic action in vivo.

Using this model, we have examined the effects of different drugs and chemicals. By now many substances have been tested [21]. The effects of several substances are summarized in Table 1. Some of them elicited anti-atherosclerotic effects in culture, some proved to be ineffective in this respect, while others even stimulated the development of atherogenic processes.

\section{Cardiovascular Drugs}

Three classes of cardiovascular drugs: calcium antagonists, beta-blockers and nitrates have been tested on our cellular model. These drugs are widely used in clinic for therapy of various disorders resulting from atherosclerosis of different arteries. We attempted to find out how calcium antagonists, beta-blockers and nitrates affect atherosclerotic indices of arterial cells.

First, we examined the effects of calcium antagonists on major atherosclerotic indices. It has been found that calcium antagonist, verapamil, has a positive effect on all atherosclerotic cellular indices. Within $48 \mathrm{hrs}$, verapamil added to culture reduced total intracellular cholesterol level by 3 -fold, sharply decreased the $\left[{ }^{3} \mathrm{H}\right]$ thymidine incorporation into cellular DNA, i.e. suppressed cell proliferative activity, and inhibited the collagen synthesis by cultured cells $[38,39]$. Thus, this drug has a direct anti-atherosclerotic effect at the arterial cell level.

Several calcium antagonists: nifedipine, darodipine, isradipine, nicardipine, nitrendipine, felodipine, tiapamil, gallopamil, diltiazem, papaverin, nicardipine, and others were also tested. Verapamil and nifedipine proved to be the most effective [49,55]. Within $24 \mathrm{hrs}$ of incubation with cultured cells all calcium antagonists substantially inhibited $\left[{ }^{3} \mathrm{H}\right]$ thymidine incorporation and reduced intracellular cholesterol level $[54,55]$. Thus, calcium antagonists produce a direct anti-atherosclerotic effect on the vascular cells normalizing the major atherosclerotic cell parameters. 


\begin{tabular}{ll}
\hline Agent & References \\
\hline ANTI-ATHEROSCLEROTIC & \\
\hline Cyclic AMP elevators & {$[39,42-45]$} \\
\hline Prostacyclin & {$[39,46-50]$} \\
\hline Prostaglandin $E_{2}$ & {$[39,46,51]$} \\
\hline Artificial HDL & {$[52]$} \\
\hline Antioxidants & {$[39]$} \\
\hline Calcium antagonists & {$[39,49,50,53-56]$} \\
\hline Trapidil and trapidil derivatives & {$[57,58]$} \\
\hline Lipoxygenase inhibitors & {$[51]$} \\
\hline Lipostabil & {$[39]$} \\
\hline Mushroom extracts & {$[59]$} \\
\hline PRO-ATHEROGENIC & {$[39]$} \\
\hline Beta-blockers & {$[55,60]$} \\
\hline Thromboxane A 2 & {$[49,50]$} \\
\hline Phenothiazines & {$[39]$} \\
\hline INDIFFERENT & {$[55]$} \\
\hline Cholestyramine & {$[305$} \\
\hline
\end{tabular}

Table 1. Substances tested on cellular model

In addition to anti-atherosclerotic effects imitating the regression of atherosclerosis, antiatherogenic effects in culture imitating prevention of atherosclerosis were studied. Table 2 demonstrates the major differences between these two approaches. In the case of anti-atherosclerotic effect the regression of atherosclerosis is imitated, whereas in the case of antiatherogenic effect, the prevention of atherosclerosis is imitated. In the first case the cells obtained from an atherosclerotic plaque are used, while in the second type of experiments cells derived from unaffected intima are employed. When anti-atherosclerotic effect is examined, cells are cultured in the presence of a standard fetal calf serum, while in the experiments on anti-atherogenic effect - atherogenic serum obtained from coronary heart disease patients is added to culture. This serum induces the accumulation of cholesterol and stimulates other atherogenic manifestations in cultured cells [61-64]. In the case of anti-atherosclerotic effect the efficacy of a drug is judged upon by its ability to decrease an elevated content of cholesterol in cultured atherosclerotic cells but in the case of anti-atherogenic effect, the efficacy of a drug is judged upon by the ability to prevent the deposition of intracellular cholesterol in normal cells. 
Four-hour preincubation of cultured cells with verapamil led to complete prevention of the serum atherogenic effect [65]. Thus, verapamil possesses not only an atherosclerotic effect in culture causing the regression of atherosclerotic manifestations at the cellular level but also elicits an anti-atherogenic, i.e. preventive effect, eliminating atherogenic potential of the serum.

\begin{tabular}{ll}
\hline ANTI-ATHEROSCLEROTIC & ANTI-ATHEROGENIC \\
\hline Regression & Prevention \\
\hline Atherosclerotic plaque & Uninvolved intima \\
\hline Standard (nonatherogenic) serum & Atherogenic patients' serum \\
\hline Cholesterol fall & Prevention of cholesterol accumulation \\
\hline
\end{tabular}

Table 2. Anti-atherosclerotic and anti-atherogenic drug effects in culture

The effect of several calcium antagonists on primary cholesterol accumulation in cultured cells induced by the patients' serum was tested. Verapamil and nifedipine completely inhibited the accumulation of intracellular cholesterol induced by the serum while other calcium antagonists: diltiazem, nicardipine, isradipine, darodipine rather substantially reduced cholesterol accumulation [65]. As it is known, the examined calcium antagonists manifested anti-atherogenic action in vivo inhibiting the development of experimental atherosclerosis in animals $[66,67]$. Thus, our in vitro data obtained on cellular model correspond to the in vivo observations. One can conclude that calcium antagonists elicit not only anti-atherosclerotic but also anti-atherogenic, i.e. preventive effect at the arterial cell level.

Nitrates and beta-blockers have been tested to reveal their action on atherosclerotic cellular indices. Nitrates had no effect on proliferative activity of atherosclerotic cells and practically did not affect the cholesterol level [55]. On the other hand, all the examined beta-blockers, propranolol, alprenolol, metoprolol, pindolol, and timolol, more or less increased atherosclerotic manifestations, i.e. all of these drugs exhibited atherogenic activity in culture $[55,60]$. If beta-blockers manifest a similar action in vivo, one may assume that these drugs are atherogenic and realize the atherogenic action at the arterial cell level. Apparently, nitrates are neutral, indifferent in this respect.

The influence of cardiovascular drugs on atherosclerosis-related effects of each other was studied. The study was focused on metoprolol, nifedipine and nitroglycerin, the drugs widely used in clinic [55]. Metoprolol caused an elevation of intracellular cholesterol, nifedipine reduced the cholesterol level while nitroglycerin was without effect on this index. The use of nifedipine on the background of metoprolol did not modify the anti-atherosclerotic action of the calcium antagonist. In this combination atherogenic action of metoprolol was not revealed. The application of metoprolol in combination with nitroglycerin led to the elimination of an atherogenic effect of the beta-blocker. Nifedipine used together with metoprolol and nitroglycerin was just as effective as in the absence of these drugs. Thus, nifedipine produces its anti-atherosclerotic effects both by itself and in combination with widely used nitrates and beta-blockers. These data suggest one important conclusion. Atherogenic 
action of beta-blockers can be inhibited if a beta-blocker is used in combination with a calcium antagonist or nitrate. This finding allows to hoping that in the nearest future it will be possible to develop beta-blockers devoid of atherogenic side effects.

Thus, three classes of cardiovascular drugs reveal different influence on cellular manifestation of atherosclerosis. Calcium antagonists exhibit anti-atherosclerotic action. On the contrary, beta-blockers are atherogenic. Nitrates are neutral, indifferent in this respect. Our data obtained on cellular model were supported by results of clinical study. Loaldi et al. have reported that long-term per oral administration of propranolol aggravates coronary atherosclerosis in patients with angina of effort as compared with the calcium antagonists, nifedipiene, and isorobide dinitrate [68]. Nifedipine produced the best effect on coronary atherosclerosis by suppressing the development of existing and preventing the appearance of new atherosclerotic lesions. Isosorbide dinitrate was less effective in this respect, while with propranolol therapy the situation was the worst. These clinical observations encourage us to develop anti-atherosclerotic therapy using our cell culture model.

\section{Ex Vivo Model}

All the above conclusions and hypotheses are based on the data obtained in in vitro experiments. Obviously, the question arises, whether anti-atherosclerotic effects of calcium antagonists and atherogenic effects of beta-blockers can be manifested in vivo and what is the optimal anti-atherosclerotic therapy based on calcium antagonists and other drugs.

To optimize anti-atherosclerotic and anti-atherogenic drug therapy, ex vivo model was developed. In case of ex vivo model not drug but blood serum taken from patients after oral drug administration is added to cultured cells.

Calcium antagonists, verapamil and nifedipine, and beta-blockers, propranolol and pindolol, were examined using ex vivo model. Within 2-4 hrs after nifedipine or verapamil administration, the patient's serum had anti-atherosclerotic properties, i.e. it was able to cause a fall in the intracellular cholesterol and inhibited atherosclerotic cell proliferation [55,56]. On the contrary, the serum of patients who received propranolol or pindolol was pro-atherogenic. Its pro-atherogenic properties manifested themselves at the arterial cell level in the rise of intracellular cholesterol and stimulation of cell proliferation [55,56]. This finding allows to assuming that not only in vitro, but in vivo as well, calcium antagonists and betablockers are anti-atherosclerotic and atherogenic drugs, respectively.

The effect of nifedipine on serum properties during a prolonged course was assessed. A patient was on nifedipine for 7 days. He received $20 \mathrm{mg}$ doses three times a day with an 8-hr interval. Twenty-eight days after regular nifedipine therapy the initial atherogenicity of the patient's serum was substantially lower than at the beginning. Directly after a dose of nifedipine the atherogenicity was practically completely eliminated [65]. On the contrary, as a result of a prolonged therapy with a beta-blocker, propranolol, patient's serum acquired stable atherogenic properties. At the beginning of the course the serum of this patient was nona- 
therogenic, however, 28 days of regular propranolol therapy led to the emergence of atherogenicity revealed even before the drug administration [65]. Thus, a single dose of betablockers brings about temporary atherogenicity of the serum. Prolonged therapy with betablockers leads to the emergence of stable atherogenic properties of patients' blood serum.

\section{Optimization of Dietary Therapy}

Cellular model can be used not only to test drugs but foodstuffs as well. We have investigated an anti-atherosclerotic, i.e. therapeutic, causing regression of atherosclerosis, and antiatherogenic, i.e. preventive activity of certain mushroom species and sea products.

Previously we have shown that alcohol and water extracts from 20 Korean mushroom species cause anti-atherosclerotic and anti-atherogenic activity in cell culture [59]. Thirteen of the 20 extracts tested were anti-atherosclerotic in culture, i.e. they caused a decrease in the cellular cholesterol and/or inhibited proliferation of atherosclerotic cells. Ten of 20 tested extracts displayed anti-atherogenic activity in addition to anti-atherosclerotic effects. Four mushroom species were chosen for the study of anti-atherosclerotic effects ex vivo. Cultivation of atherosclerotic cells during $24 \mathrm{hrs}$ in the presence of serum from healthy subjects who had had mushroom meals resulted in a $21-30 \%$ decrease in the cellular cholesterol level, i.e. caused anti-atherosclerotic effect [59]. The atherogenic serum obtained from atherosclerotic patients after dietary mushroom consumption partly (30-41\%) lost its ability to increase the cellular cholesterol content [59]. Thus, tested mushrooms exhibited anti-atherosclerotic and anti-atherogenic effects on ex vivo model.

Among sea products mollusk and krill meat were tested [36]. Specifically, the patients were given canned meat of a mollusk belonging to genus Buccinum. Two hours after a single dietary load the patient's blood serum acquired marked anti-atherosclerotic properties. The addition of this serum to cultured atherosclerotic cells led to a fall in intracellular cholesterol level [36]. Four hours later the anti-atherosclerotic properties of the serum became even more prominent.

Patients of another group had an initially atherogenic serum causing more then 2-fold increase in cholesterol content of cells derived from normal intima. These patients received a single dietary load of Antarctic krill meat. Two hours later the atherogenicity of their blood serum decreased and four hours later it was practically absent [36]. Thus, krill meat exhibits a preventive anti-atherogenic action on arterial cells.

The results obtained suggest that the krill meat can be employed in diets aimed at the prevention of atherosclerosis. To develop a dietary therapy based on the krill meat, the effective dose and proper regimen should be established. As the first step to develop a dietary therapy, the below outlined study was undertaken to determine the effective dose.

The patients' blood sera were analyzed for atherogenicity. Patients whose blood serum had an atherogenic potential were included in the study. The blood was collected from each patient before, 2 and $4 \mathrm{hrs}$ after a dose of krill meat. This protocol was repeated on the next day 
with another dose of krill meat. Blood serum samples were added to a culture of subendothelial cells isolated from uninvolved human aortic intima, and intracellular cholesterol accumulation was assessed in each case. Anti-atherogenic activity of krill meat was evaluated by the ability to reduce serum atherogenicity which manifested in cholesterol accumulation in cultured cells (Figure 2). The dose-effect dependence was revealed by comparing the efficacy of two doses. The efficacy of each dose was evaluated by the analysis of at least 6 sera obtained from different patients. In can be seen from that the krill meat elicits an anti-atherogenic effect at a dose of 10-20 g, half maximum effect was reached at a dose of $30 \mathrm{~g}$ and the maximum effect - at a dose of $50 \mathrm{~g}$.

We believe that this approach will be useful in the development and optimization of antiatherosclerotic and anti-atherogenic diet therapies.

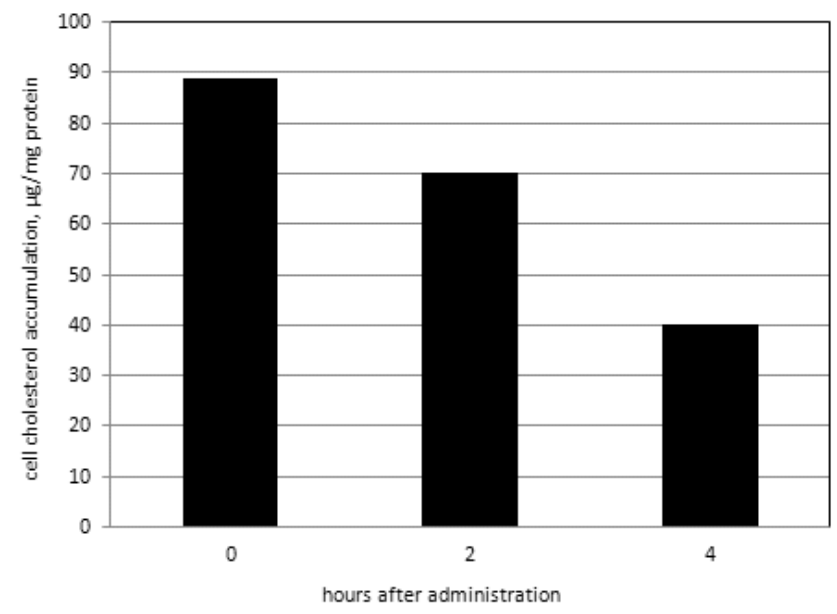

Figure 2. Antiatherogenic effect of krill meat on blood serum of atherosclerotic patients

Blood serum atherogenicity was determined using primary culture of cells derived from uninvolved intima of the human aorta.

\section{Natural Products for Anti-Atherosclerotic Therapy}

Anti-atherogenic effects of dietary products promote the development of anti-atherosclerotic therapy on the basis of natural products. Atherosclerosis develops over many years, so the anti-atherosclerotic therapy should be long-term or even lifelong therapy. For such a longterm therapy conventional medicine might not work. Drugs based on natural products can be a good alternative. 
We have tested numerous natural products' extracts to reveal their effects on blood atherogenicity, i.e., a capacity to prevent intracellular cholesterol accumulation caused by atherogenic blood sera from patients. Table 3 presents effective natural products only. As a fact, among tested agents were revealed not only anti-atherogenic but also pro-atherogenic and neutral. Among antiatherogenic natural products the most effective was garlic.

\begin{tabular}{lc}
\hline & $\begin{array}{c}\text { Atherogenicity } \\
\text { decrease, } \%\end{array}$ \\
\hline Spirulina platensis & 51 \\
\hline Allium cepa & 21 \\
\hline Beta vulgaris & 31 \\
\hline Triticum vulgaris & 70 \\
\hline Glycyrrhiza glabra & 55 \\
\hline Salsola collina & 11 \\
\hline Allium sativum & $\mathbf{7 7}$ \\
\hline Pinus sylvestris & 52 \\
\hline
\end{tabular}

Table 3. Anti-atherogenic effects of natural products

We extended investigation of the in vitro effect of garlic extract on lipids of cultured human aortic cells. We have earlier shown that lipid accumulation in human aortic cells is accompanied by stimulation of other cellular manifestation of atherosclerosis, namely: proliferation and extracellular matrix synthesis $[41,63]$. Thus, investigation of garlic action on cellular lipid parameters is closely related to the study of the mechanism of garlic anti-atherosclerosis effect.

A direct influence of garlic on atherosclerosis is discussed [70-73]. The anti-atherosclerotic effect of garlic has been attributed to its hypolipidemic activity. Experimental and clinical data have clearly demonstrated that garlic reduces blood cholesterol and LDL levels [74,75]. The cholesterol lowering effect of garlic results from inhibition of hepatic hydroxymethylglutaryl coenzyme A (HMG-CoA) [76]. In contrast to these studies, we examined not the hyperlipidemic but the direct anti-atherosclerotic-related and anti-atherogenic-related effects of garlic, i.e., the ability of garlic to act directly on atherosclerotic process in the vessel wall. To investigate anti-atherosclerotic-related (therapeutic) effect we used smooth muscle cells cultured from atherosclerotic plaques of human aorta. To study anti-atherogenic-related (preventive) effect we imitated atherogenesis in primary cultures of smooth muscle cells derived from grossly uninvolved human aortic intima by adding atherogenic blood serum of patients with angiographically assessed coronary atherosclerosis. Garlic decreased triglyceride, cholesteryl ester and free cholesterol contents of cells cultured from atherosclerotic plaque and prevented atherogenic serum-induced accumulation of these lipids in cells cultured from grossly normal aorta, i.e., elicited direct anti-atherosclerotic-related (therapeutic) and 
anti-atherogenic-related (preventive) effects. Garlic inhibits ACAT and stimulates CEH, thus displaying a direct influence on synthesis and degradation of cholesteryl esters in the cell. This finding may explain direct anti-atherosclerotic effects of garlic.

Further investigations of garlic anti-atherosclerotic effects included ex vivo study and animal model study. Both types of studies confirmed the in vitro effects of garlic. Finally, we have developed a drug on the basis of garlic powder and carried out atherosclerosis regression clinical study of this drug.

\section{Atherosclerosis Regression Clinical Studies of Natural Products}

The AMAR study (Atherosclerosis Monitoring and Atherogenicity Reduction) was designed to estimate the effect of two-year treatment with time-released garlic-based drug Allicor on the progression of carotid atherosclerosis in asymptomatic men in double-blinded placebocontrolled randomized clinical trial. The primary outcome was the rate of atherosclerosis progression, measured by high-resolution B-mode ultrasonography as the increase in carotid intima-media thickness (IMT) of the far wall of common carotid arteries.

Atherosclerosis affects most vascular beads, and noninvasive imaging of superficial arteries by ultrasound has been recognized as a surrogate measure of overall atherosclerotic burden in numerous studies. Extracoronary atherosclerotic lesions can be quickly and safely evaluated in the carotids, femoral arteries, and the abdominal aorta. The grade of atherosclerosis in extracoronary sites correlates with a greater number of standard risk factors and, more importantly, with greater cardiac risk [77]. Of the peripheral arterial surrogates, carotid atherosclerosis has been most closely correlated with coronary artery disease [78-82]. Peripheral arterial ultrasonography is regarded to be a sensitive tool for the detection of early atherosclerosis and may be useful in assessing response to therapy. Thickening of the intima-media of the arterial wall is the earliest detectable anatomic change in the development and progression of atherosclerosis. High-resolution B-mode ultrasonography is widely used for noninvasive quantification of carotid IMT as a measure of subclinical atherosclerosis [83]. Carotid IMT is believed to be a marker of generalized atherosclerosis and is predictive of clinical cardiovascular events [79,81,84-88]. Thus, ultrasound imaging of intima-media thickening in carotid arteries served as a means of monitoring atherosclerosis during Allicor long-term treatment. Indeed, Allicor significantly reduced carotid arterial intima-media thickness compared to baseline and the placebo group. In Allicor recipients, a significant increase in the IMT in one or both carotid arteries was observed in $30(32.2 \%)$ patients, and was significantly reduced in $44(47.3 \%)$ patients. In 8 patients $(8.6 \%)$ there were no significant IMT changes in either the carotid artery, and in the remaining 11 patients $(11.8 \%)$ divergent changes were observed, i.e. IMT increased in one carotid artery and decreased in the other. IMT lesion progression was observed in 50 (48.5\%) placebo cases, and decreased significantly in one or both arteries in $31(30.1 \%)$ patients. Stable situation was observed in 11 $(10.7 \%)$, and divergent changes occurred in the remaining $7(6.8 \%)$ patients. The difference in the IMT changes between Allicor and placebo recipients was statistically significant (Pear- 
son's chi-square 9.788, $\mathrm{P}=0.020$ ). Thus, while spontaneous atherosclerosis progression prevailed in the placebo group, Allicor beneficially impacted early carotid atherosclerosis significantly increasing lesion regressions and reducing the net number of progressive lesions (Figure 3). The trend to IMT reduction in Allicor recipients was observed already after first 3 months of the study, and became statistically significant different from the baseline measures as well as from placebo group after the first 12 months of treatment. At the end of the two-year study the difference between placebo and Allicor recipients increased and remained statistically significant. The overall lesion progression was clearly different in the treated and untreated groups. IMT in the common carotid artery rose $0.015 \pm 0.008 \mathrm{~mm}$ annually and above a mean baseline IMT of $0.931 \pm 0.009 \mathrm{~mm}$ in the placebo group, and fell in Allicor-treated patients at a rate of $-0.022 \pm 0.007 \mathrm{~mm}$ per year $(\mathrm{P}=0.002)$. Though the benefit of Allicor was more pronounced in year $1(-0.028 \pm 0.008 \mathrm{~mm})$ it remained significant and as a statistically identical significant difference in year $2(-0.016 \pm 0.007)$.

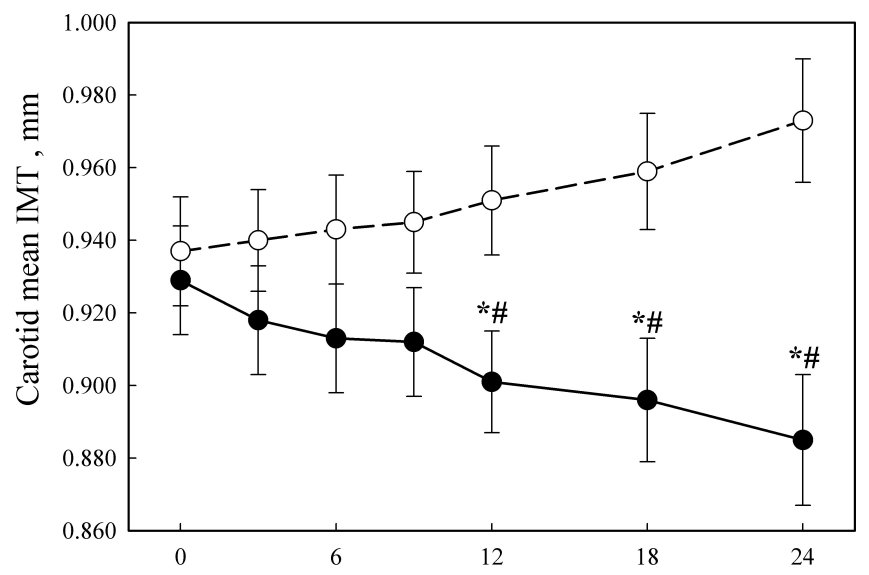

Time, months

Figure 3. The dynamics of IMT changesSolid circles, Allicor-treated patients; open circles, placebo patients. * , significant IMT change as compared to baseline, $\mathrm{P}<0.05$; \#, significant difference from placebo group, $\mathrm{P}<0.05$.

The beneficial effects of Allicor were also revealed in analysis of subgroups of patients who had significant increase or reduction in IMT. IMT progression was almost 2.5 fold higher in the 50 patients in the placebo group with progress $(0.070 \pm 0.016 \mathrm{~mm})$ than in Allicor-treated patients with atherosclerosis progression $(n=30,0.029 \pm 0.011 \mathrm{~mm}$ increase, $\mathrm{P}=0.038)$. Similarly, spontaneous atherosclerosis regression in placebo recipients $(n=31)$ was half as prominent $(-0.041 \pm 0.014 \mathrm{~mm})$ than in Allicor-treated patients $(\mathrm{n}=44,-0.082 \pm 0.015 \mathrm{~mm}, \mathrm{P}=0.049)$.

The results obtained in our study are generally in good coincidence with the data from recent double-blinded placebo-controlled randomized study by Koscielny et al. [89]. It has been demonstrated that 4-year treatment with garlic-based drug Kwai inhibited the increase 
in the volume of atherosclerotic plaques in carotid and femoral arteries by $5-18 \%$. The agedependent representation of the plaque volume has shown an increase between 50 and 80 years that was diminished under garlic treatment by $6-13 \%$ related to 4 years. So, with garlic application the plaque volume in the whole collective remained practically constant within the age-span of 50-80 years [89].

Overall, the regression of subclinical atherosclerosis was much more frequently observed in asymptomatic men who randomly received Allicor than in those who received placebo. A rather high proportion of patients in placebo group who demonstrated spontaneous regression, especially at early stages of atherosclerosis, reflects an interesting but poorly understood aspect of vascular biology that requires further study. The decrease in IMT achieved during the AMAR study is quite comparable with the results of most successful trials with other compounds (Table 4). Although, these studies employed potent lipid-lowering agents either calcium antagonists whose beneficial effects of treatment were attributed to reduction in LDL cholesterol, the major risk factor for atherosclerosis development, or arterial wall stress.

\begin{tabular}{llccc}
\hline \multirow{2}{*}{ Trial } & Medication & \multicolumn{2}{c}{ Mean annual IMT change, $\mathbf{m m}$} & Reference \\
\cline { 3 - 5 } & & placebo & treatment & \\
\hline \hline PLAC II & Pravastatin & 0.068 & 0.059 & {$[91]$} \\
\hline KAPS & Pravastatin & 0.029 & 0.010 & {$[90]$} \\
\hline ASAP & Simvastatin & - & -0.009 & {$[92]$} \\
\hline PREVENT & Amlodipine & 0.011 & -0.015 & {$[93]$} \\
\hline ASAP & Atorvastatin & - & -0.020 & {$[92]$} \\
\hline CLAS & Cholestipol, niacin & 0.010 & -0.020 & {$[94,95]$} \\
\hline MARS & Lovastatin & 0.015 & -0.028 & {$[94,96]$} \\
\hline VHAS & Verapamil & - & -0.028 & {$[97]$} \\
\hline AMAR & Allicor & 0.015 & -0.022 & This study \\
\hline
\end{tabular}

Table 4. The comparative data from clinical trials on carotid atherosclerosis regression

The main scientific goal of the given double-blinded, placebo-controlled randomized study was to test the hypothesis that long-term lowering of serum atherogenicity may prevent the initial stage of atherogenesis, namely, the excessive deposition of cholesterol in the cells of the arterial wall, thus inhibiting further formation of atherosclerosis lesion [41,62].

At the baseline, the sera from 17 patients in placebo group (16.5\%) did not induce significant cholesterol accumulation in cultured cells, while the sera from other 86 patients were atherogenic, i.e. induced a statistically significant (1.2- to 3.9-fold) increase in intracellular cholesterol content (mean result, $166.3 \pm 5.5$, \% of control value). In Allicor-treated patients, 23 
patients $(24.7 \%)$ had non-atherogenic sera, and in other 70 patients the sera increased intracellular cholesterol by 1.2 - to 3.5 -fold (mean result, $172.1 \pm 5.8, \%$ of control value).

Among patients with non-atherogenic sera at the baseline, in placebo recipients blood serum atherogenicity arrived in 11 cases during the study; in Allicor-treated patients at the end of the study serum atherogenicity was revealed in 9 cases, and in other 14 patients the sera remained non-atherogenic. The difference between Allicor and placebo recipients was statistically significant (Pearson's chi-square 11.023, $\mathrm{P}<0.001$ ). Thus, Allicor treatment prevented the upraise of blood serum atherogenicity.

Among patients with initially atherogenic sera, in placebo group blood serum atherogenicity spontaneously decreased in 26 patients, did not change significantly in 28 patients, and in 32 cases there was further increase in blood serum atherogenic potential. On the opposite, in Allicor group serum atherogenicity was decreased in 39 patients by the end of the study, remained unchanged in 18 patients, and further increase in serum ability to induce intracellular cholesterol accumulation was observed only in 13 cases. Again, the difference between Allicor and placebo recipients was statistically significant (Pearson's chi-square 11.274, $\mathrm{P}=0.004$ ). Thus, Allicor also induced a fall in blood serum atherogenicity, if it existed at the beginning of treatment.

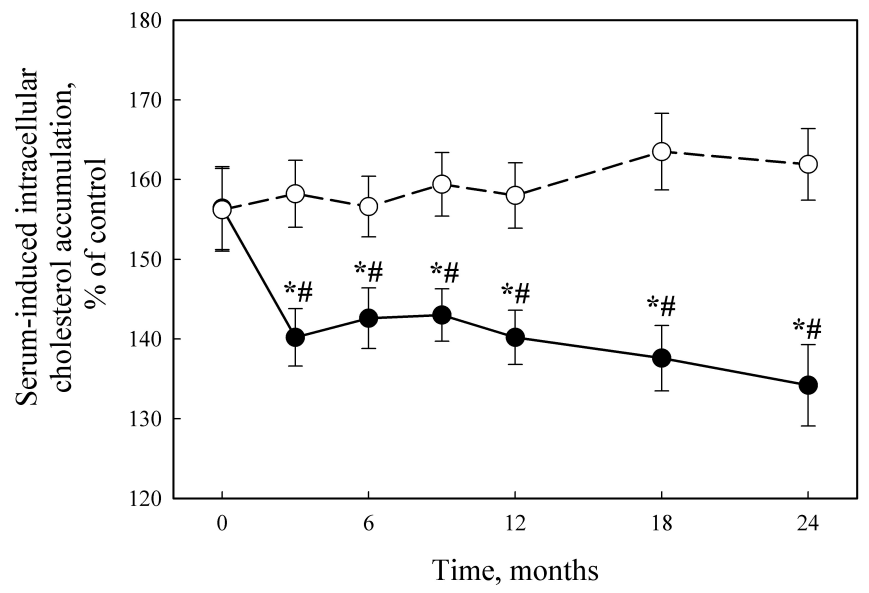

Figure 4. The dynamics of serum atherogenicity changesSolid circles, Allicor-treated patients; open circles, placebo patients. ${ }^{*}$, significant IMT change as compared to baseline, $\mathrm{P}<0.05$; $\#$, significant difference from placebo group, $\mathrm{P}<0.05$.

The overall dynamic of changes in serum atherogenicity is presented in Figure 4 . At the baseline, serum taken from patients was able to induce 1.56-fold increase in intracellular cholesterol content in cell culture test. In the placebo group, the mean level of serum atherogenic potential did not change significantly during two years of the study. On the opposite, in Allicor-treated patients the mean value for the ability of serum to induce intracellular lip- 
id accumulation was significantly lowered $(\mathrm{P}=0.016)$ approximately by $30 \%$ of the initial level $(95 \%$ CI: $16.9,41.0)$ already after first 3 months of study, and this effect was maintained during the study. General linear model analysis has demonstrated the statistically significant difference in the dynamic of changes in serum atherogenicity between Allicor-treated and placebo groups $(\mathrm{P}=0.008)$.

The presence or absence of serum atherogenicity at the baseline, as well as the extent of serum-induced intracellular cholesterol accumulation at the baseline, did not correlate with the following changes in IMT. However, the statistically significant correlation has been revealed between the changes in blood serum atherogenicity during the study and the changes in intima-media thickness of common carotid arteries ( $r=0.144, \mathrm{P}=0.045$ for the total study sample). In patients with initially non-atherogenic sera, the correlation between changes in atherogenicity and IMT was stronger $(r=0.342, \mathrm{P}=0.031)$. This correlation is explained mainly by the arrival of serum atherogenicity during follow-up in a subgroup of placebo recipients with initially non-atherogenic sera; in them the correlation between increase of atherogenicity and IMT dynamics was the highest $(\mathrm{r}=0.517, \mathrm{P}=0.034)$.. In patients with initially atherogenic sera, the correlation between changes in atherogenicity and IMT in total group did not reach statistical significance $(\mathrm{r}=0.147, \mathrm{P}=0.067)$, but in Allicor-treated patients in most of whom the decrease in serum atherogenicity was observed, the above parameters correlated well $(\mathrm{r}=0.254, \mathrm{P}=0.034)$.

There is a substantial experimental background to explain the possible mechanisms underlying a direct anti-atherosclerotic action of Allicor. The components of garlic can regulate two main intracellular enzymes responsible for cholesterol intracellular metabolism. Garlic extract stimulates cholesteryl ester hydrolase and inhibits acetyl coenzyme A : cholesterol acyl transferase, thus diminishing intracellular content of cholesteryl esters [98]. Additionally, garlic extract inhibits cellular proliferative activity and the synthesis of connective tissue matrix components $[98,99]$. Allicor also possesses antioxidant activity and lowers LDL susceptibility to oxidation [99]. Allicor prevents serum-induced cholesterol accumulation in cells cultured in the presence of patient's serum taken after single dose of Allicor administration; in other words, it reduces serum atherogenic potential [99]. In animal studies, garlicbased preparations inhibit the formation of neointimal thickening in cholesterol-fed rabbits [100]. So, it could be easily proposed that long-term Allicor treatment produced a direct antiatherosclerotic effect due to the prevention of lipid deposition and depletion of cholesterol pool already accumulated in arterial wall.

Garlic contains a variety of organosulfur compounds, amino acids, vitamins and minerals [101]. Some of the sulfur-containing compounds such as allicin, ajoene, S-allylcysteine, Smethylcysteine, diallyl disulfide and sulfoxides may be responsible for antiatherosclerotic activity of garlic $[98,100]$. Many garlic-based products are present on the market now. As compared to other garlic preparations, dehydrated garlic powder is thought to retain the same ingredients as raw garlic, both water-soluble and organic-soluble, although the proportions and amounts of various constituents may differ significantly [102,103]. Allicor contains just garlic powder; on the other hand, it possesses a prolonged mode of action, as its antiatherogenic effect lasts for 12-16 hours after single dose administration [99]. So, Allicor 
differs greatly from other garlic-based preparations and may have considerable benefits in medicinal use.

On the whole, the results of our study demonstrate that long-term treatment with time-released garlic-based drug Allicor provides a direct anti-atherosclerotic effect on carotid atherosclerosis. Being the remedy of natural origin, Allicor is safe with the respect to adverse effects and allows even perpetual administration, which may be quite necessary for prevention and treatment of subclinical atherosclerosis. These results encouraged clinical trials of two other drugs based on natural products, including: Inflaminat, possessing anti-cytokine activity and the phytoestrogen-rich drug Karinat, designed for postmenopausal women.

Atherosclerosis is regarded as a pathological process with elements of local aseptic inflammation, while inflammatory cytokines play a role at every stage of atherosclerosis development [104-107]. In this regard, drugs with systemic anti-inflammatory action may be effective for the prevention of atherosclerosis. In our study, we investigated the atherosclerosis regression effect of natural drug Inflaminat based on calendula, elder and violet. These plants are widely used in herbal medicine as anti-inflammatory agents. In a pilot study of Inflaminat using a protocol similar to the AMAR study Inflaminat demonstrated atherosclerosis regression effects and statistically significant difference from the baseline as well as from placebo group (Table 5). Thus, Inflaminat possesses atherosclerosis regression effect in asymptomatic men.

\begin{tabular}{lccc}
\hline & Inflaminat & Placebo & $\mathbf{p}^{* *}$ \\
\hline Number of participants & 81 & 77 & - \\
\hline \multirow{3}{*}{ IMT, $\mu \mathrm{m}$} & $-62 \pm 48$ * & $42 \pm 75$ & \\
& $(-91 ;-32)$ & $(-9 ; 93)$ & 0.002 \\
& $\mathrm{p}=0,002$ & $\mathrm{p}=0,109$ & \\
\hline
\end{tabular}

Table 5. Carotid IMT changes in 1-year Inflaminat pilot study* significant differences, $p<0.05$, Wilcoxon's signed ranked test; ${ }^{* *}$ statistical significance of differences was estimated by Mann-Whitney U-test.

Atherosclerosis prevention in postmenopausal women is a striking problem, since modern medicine does not provide any effective approach. Hormone replacement therapy was rejected as a tool for atherosclerosis prevention in women due to the negative results of recent studies - WHI, PEPI and HERS [108-113]. So, the development of novel approaches is highly demanded. Phytoestrogens are often regarded as a possible alternative to hormone replacement therapy, but practically nothing is known on their effects on atherosclerosis.

We screened many natural phytoestrogen-rich components for their antiatherogenic activity using an ex vivo test system [39,61,114-117]. The most promising of these compounds were: garlic powder, extract of grape seeds, green tea leafs and hop cones - all produced a significant antiatherogenic effect. On the basis of their combination, the novel isoflavonoid-rich dietary supplement Karinat was developed. It produces the most efficient antiatherogenic effect in cell culture models and is characterized by improved phytoestrogen profile, provid- 
ing additional amounts of biologically active polyphenols including resveratrol, genisteine and daidzeine that are claimed to produce some effects on atherosclerosis development. Karinat also contains additional amounts of $\beta$-carotene, $\alpha$-tocopherol and ascorbic acid to provide the necessary daily intake of antioxidants

A randomized double-blinded placebo-controlled pilot clinical study on atherosclerotic effect of Karinat was performed in healthy peri- and postmenopausal women to understand the risks and benefits of phytoestrogen therapy in relation to atherosclerosis progression. The primary endpoint was the annual rate of changes in common carotid artery intima-media thickening, and the secondary endpoint was the dynamics of climacteric syndrome, that is monitored only in perimenopausal women. Table 6 demonstrates the effect of Karinat treatment on the dynamics of carotid atherosclerosis in postmenopausal women. In the placebo group an increase in the average IMT of more than $100 \mu \mathrm{m}$ per year was observed. Thus, the rate of the natural history of atherosclerosis in postmenopausal women is extremely high: the average increase in IMT is $13 \%$ per year, and growth of atherosclerotic plaques of $40 \%$ per year.

\begin{tabular}{lcccc}
\hline & Karinat & $\mathbf{P}$ & Placebo & $\mathbf{P}$ \\
\hline Number of participants & 80 & - & 77 & - \\
\hline IMT, $\mu \mathrm{m}$ & $+6(85)$ & $\mathrm{p}<0.05$ & $+111(91)$ & $\mathrm{p}<0.02$ \\
\hline Plaques, scores & $+0,21(0,59)$ & 0,009 & $+0,31(0,55)$ & $<0,001$ \\
\hline
\end{tabular}

Table 6. Carotid IMT changes in 1-year Karinat pilot study on postmenopausal women

In the Karinat group a completely different picture was observed. The average IMT of carotid arteries was not changed (statistically insignificant increase of $6 \mu \mathrm{m}$ per year, i.e. less than $1 \%$ ). However, the progression of existing plaques by $27 \%$ per year was detected.

The results of quantitative measurements of the degree of atherosclerosis in the dynamics have shown that the use of phytoestrogen complex in postmenopausal women almost completely suppresses the formation of new atherosclerotic lesions and 1.5-fold slows the progression of existing lesions.

Thus, as in the AMAR trial Inflaminat caused regression of carotid atherosclerosis while Karinat prevented its development. It should be noted that the anti-atherosclerotic effects of drugs based on natural products are not inferior to the effects of such drugs as statins and calcium antagonists (Table 4). Thus, natural products can be considered as promising drugs for anti-atherosclerotic therapy.

\section{Conclusion}

This review illustrates the use of cultured human arterial cells for: 
- mass screening of drugs and chemicals (cyclic AMP elevators, calcium antagonists, prostaglandins, - blockers, antioxidants, etc.);

- investigation of the mechanisms responsible for the atherosclerosis-related effects (calcium antagonists and lovastatin);

- optimization of anti-atherosclerotic and anti-atherogenic drug and dietary therapy $(\beta$ blockers, calcium antagonists, mushrooms, krill meat).

Cell cultures enable one to perform investigation on models: - in vitro (mass screening, study of the mechanism of drug action);

- ex vivo (study of the mechanism of drug action, optimization of therapy);

- in vivo models (animals with experimental atherosclerosis) allowed us to confirm the results obtained on in vitro and ex vivo models.

The in vitro and ex vivo models can be employed to reveal and investigate of:

- direct anti-atherosclerotic activity - regression of atherosclerosis (calcium antagonists, prostaglandins, antioxidants, lipostabil, mushrooms, mollusk meat, etc.);

- direct anti-atherogenic activity - prevention of atherosclerosis (calcium antagonists, mushrooms, krill meat);

- indirect anti-atherogenic activity (lovastatin);

- atherogenic activity ( $\beta$-blockers, thromboxane, phenothiazines).

Natural products can be considered as promising drugs for anti-atherosclerotic therapy. Two-year treatment with Allicor (garlic powder) has a direct anti-atherosclerotic effect on carotid atherosclerosis in asymptomatic men. Inflaminat (calendula, elder and violet), possessing anti-cytokine activity, caused regression of carotid atherosclerosis as a result of 1year treatment of asymptomatic men. Phytoestrogen-rich drug Karinat (garlic powder, extract of grape seeds, green tea leafs, hop cones, $\beta$-carotene, $\alpha$-tocopherol and ascorbic acid) prevented development of carotid atherosclerosis in postmenopausal women.

Our basic studies have shown that cellular lipidosis is the principal event in genesis of atherosclerotic lesion. Using cellular models and natural products we have developed an approach to prevent lipid accumulation in arterial cells. This led to regression of atherosclerosis and/or prevention of its progression in patients. So, our basic findings were successfully translated into clinical practice. As a result of this translation novel approach to anti-atherosclerotic therapy was developed. On the basis of our knowledge we developed drugs possessing direct anti-atherosclerotic activity. Our clinical trial confirmed the efficacy both novel approach and novel drugs.

\section{Acknowledgements}

This work was supported by the Russian Ministry of Education and Science. 


\section{Author details}

Alexander N. Orekhov ${ }^{1 *}$, Igor A. Sobenin ${ }^{2}$, Alexandra A. Melnichenko ${ }^{3}$, Veronika A. Myasoedova ${ }^{1}$ and Yuri V. Bobryshev ${ }^{4,1}$

*Address all correspondence to: a.h.opexob@gmail.com

1 Institute for Atherosclerosis Research, Skolkovo Innovative Center, Moscow, Russia

2 Russian Cardiology Research and Production Complex, Ministry of Healthcare and Social Development, Moscow, Russia

3 Institute of General Pathology and Pathophysiology, Russian Academy of Medical Sciences, Moscow, Russia

4 Faculty of Medicine, School of Medical Sciences, University of New South Wales, Sydney, Australia

\section{References}

[1] Martin, S. S., Blumenthal, R. S., \& Miller, M. (2012). LDL cholesterol. the lower the better. The Medical Clinics of North America, 96(1), 13-26.

[2] Kruth, H. S. (2011). Receptor-independent fluid-phase pinocytosis mechanisms for induction of foam cell formation with native low-density lipoprotein particles. Current Opinion in Lipidology, 22(5), 386-393.

[3] Yuan, Y., Li, P., \& Ye, J. (2012). Lipid homeostasis and the formation of macrophagederived foam cells in atherosclerosis. Protein $\mathcal{E}$ Cell, 3(3), 173-181.

[4] Orekhov, A. N., Tertov, V. V., Mukhin, D. N., \& Mikhailenko, I. A. (1989). Modification of low density lipoprotein by desialylation causes lipid accumulation in cultured cells. Discovery of desialylated lipoprotein with altered cellular metabolism in the blood of atherosclerotic patients. Biochemical and Biophysical Research Communications, 162(1), 206-211.

[5] Orekhov, A. N., Tertov, V. V., \& Mukhin, D. N. (1991). Desialylated low density lipoprotein- naturally occurring modified lipoprotein with atherogenic potency. Atherosclerosis, 86(2-3), 153-161.

[6] Tertov, V. V., Sobenin, I. A., Gabbasov, Z. A., Popov, E. G., \& Orekhov, A. N. (1989). Lipoprotein aggregation as an essential condition of intracellular lipid accumulation caused by modified low density lipoproteins. Biochemical and Biophysical Research Communications, 163(1), 489-494.

[7] Tertov, V. V., Sobenin, I. A., Tonevitsky, A. G., Orekhov, A. N., \& Smirnov, V. N. (1990). Isolation of atherogenic modified (desialylated) low density lipoprotein from 
blood of atherosclerotic patients: separation from native lipoprotein by affinity chromatography. Biochemical and Biophysical Research Communications, 167(3), 1122-1127.

[8] Tertov, V. V., Sobenin, I. A., Orekhov, A. N., Jaakkola, O., Solakivi, T., \& Nikkari, T. (1996). Characteristics of low density lipoprotein isolated from circulating immune complexes. Atherosclerosis, 122(2), 191-199.

[9] Tertov, V. V., Kaplun, V. V., Sobenin, I. A., Boytsova, E. Y., Bovin, N. V., \& Orekhov, A. N. (2001). Human plasma trans-sialidase causes atherogenic modification of low density lipoprotein. Atherosclerosis, 159(1), 103-315.

[10] Avogaro, P., Bon, G. B., \& Cazzolato, G. (1988). Presence of a modified low density lipoprotein in humans. Arteriosclerosis, 8(6), 79-87.

[11] Krauss, R. M., \& Burke, D. J. (1982). Identification of multiple subclasses of plasma low density lipoproteins in normal humans. Journal of Lipid Research, 23(1), 97-104.

[12] Tertov, V. V., Bittolo-Bon, G., Sobenin, I. A., Cazzolato, G., Orekhov, A. N., \& Avogaro, P. (1995). Naturally occurring modified low density lipoproteins are similar if not identical: more electronegative and desialylated lipoprotein subfractions. Experimental and Molecular Pathology, 62(3), 166-172.

[13] Tertov, V. V., Sobenin, I. A., \& Orekhov, A. N. (1996). Similarity between naturally occurring modified desialylated, electronegative and aortic low density lipoprotein. Free Radical Research, 25(4), 313-319.

[14] Kirk, J. K., Davis, S. W., Hildebrandt, CA, Strachan, E. N., Peechara, M. L., \& Lord, R. (2011). Characteristics associated with glycemic control among family medicine patients with type 2 diabetes. North Carolina Medical Journal, 72(5), 345-350.

[15] Soran, H., \& Durrington, P. N. (2011). Susceptibility of LDL and its subfractions to glycation. Curr Opin Lipidol, 22, 254-261.

[16] Jiang, X., Yang, Z., Chandrakala, A. N., Pressley, D., \& Parthasarathy, S. (2011). Oxidized low density lipoproteins--do we know enough about them? Cardiovascular Drugs and Therapy, 25(5), 367-377.

[17] Orekhov, A. N., Tertov, V. V., Kabakov, A. E., Adamova, I. Yu, Pokrovsky, S. N., \& Smirnov, V. N. (1991). Autoantibodies against modified low density lipoprotein. Nonlipid factor of blood plasma that stimulates foam cell formation. Arteriosclerosis and Thrombosis, 11(2), 316-326.

[18] Lopes-Virella, M. F., \& Virella, G. (2010). Clinical significance of the humoral immune response to modified LDL. Clinical Immunology, 134(1), 55-65.

[19] Orekhov, A. N., Tertov, V. V., Mukhin, D. N., \& Kabakov, A. E. (1989). Modified (desialylated) low density lipoprotein and autoantibodies against lipoprotein cause atherogenic manifestations in cell culture. In: Descovich G.C., Gaddi A., Magri G.L., Lenzi S. (eds). Atherosclerosis and Cardiovascular Disease. Bologna: Editrice Compositori Part B;. , 4, 523-529. 
[20] Orekhov, A. N., \& Tertov, V. V. (1991). Atherogenicity of autoantibodies against low density lipoprotein. Agents and Actions, 32(1-2), 128-129.

[21] Tertov, V. V., Orekhov, A. N., Sayadyan, Kh. S., Serebrennikov, S. G., Kacharava, A. G., Lyakishev, A. A., \& Smirnov, V. N. (1990). Correlation between cholesterol content in circulating immune complexes and atherogenic properties of CHD patients' serum manifested in cell culture. Atherosclerosis, 81(3), 183-189.

[22] Tertov, V. V., Orekhov, A. N., Kacharava, A. G., Sobenin, I. A., Perova, N. V., \& Smirnov, V. N. (1990). Low density lipoprotein-containing circulating immune complexes and coronary atherosclerosis. Experimental and Molecular Pathology, 52(3), 300-308.

[23] Orekhov, A. N., Kalenich, O. S., Tertov, V. V., \& Novikov, I. D. (1991). Lipoprotein immune complexes as markers of atherosclerosis. International Journal of Tissue Reactions, 13(5), 233-236.

[24] Orekhov, A. N., Kalenich, O. S., Tertov, V. V., Perova, N. V., Novikov, Iy. D., Lyakishev, A. A., Deev, A. D., \& Ruda, M. Ya. (1995). Diagnostic value of immune cholesterol as a marker for atherosclerosis. Journal of Cardiovascular Risk, 2(5), 459-466.

[25] Kacharava, A. G., Tertov, V. V., \& Orekhov, A. N. (1993). Autoantibodies against low-density lipoprotein and atherogenic potential of blood. Annals of Medicine, 25(6), 551-555.

[26] Orekhov, A. N., Tertov, V. V., Mukhin, D. N., Koteliansky, V. E., Glukhova, M. A., Frid, M. G., Sukhova, G. K., Khashimov, K. A., \& Smirnov, V. N. (1989). Insolubilization of low density lipoprotein induces cholesterol accumulation in cultured subendothelial cells of human aorta. Atherosclerosis, 79(1), 59-70.

[27] Glukhova, M. A., Kabakov, A. E., Frid, M. G., Ornatsky, O. I., Belkin, A. M., Mukhin, D. N., Orekhov, A. N., Koteliansky, V. E., \& Smirnov, V. N. (1988). Modulation of human aorta smooth muscle cell phenotype: a study of muscle-specific variants of vinculin, caldesmon, and actin expression. Proceedings of the National Academy of Sciences of the United States of America, 85(24), 9542-9546.

[28] Orekhov, A. N., Tertov, V. V., Mukhin, D. N., Koteliansky, V. E., Glukhova, M. A., Khashimov, K. A., \& Smirnov, V. N. (1987). Association of low-density lipoprotein with particulate connective tissue matrix components enhances cholesterol accumulation in cultured subendothelial cells of human aorta. Biochimica et Biophysica Acta, 928(3), 251-258.

[29] Tertov, V. V., Sobenin, I. A., Gabbasov, Z. A., Popov, E. G., \& Orekhov, A. N. (1989). Lipoprotein aggregation as an essential condition of intracellular lipid accumulation caused by modified low density lipoproteins. Biochemical and Biophysical Research Communications, 163(1), 489-494.

[30] Tertov, V. V., Orekhov, A. N., Sobenin, I. A., Gabbasov, Z. A., Popov, E. G., Yaroslavov, A. A., \& Smirnov, V. N. (1992). Three types of naturally occurring modified lipo- 
proteins induce intracellular lipid accumulation due to lipoprotein aggregation. Circulation Research, 71(1), 218-228.

[31] Aksenov, D. V., Medvedeva, L. A., Skalbe, T. A., Sobenin, I. A., Tertov, V. V., Gabbasov, Z. A., Popov, E. V., \& Orekhov, A. N. (2008). Deglycosylation of apo B-containing lipoproteins increase their ability to aggregate and to promote intracellular cholesterol accumulation in vitro. Archives of Physiology and Biochemistry, 114(5), 349-356.

[32] Rekhter, M. D., Andreeva, E. R., Mironov, A. A., \& Orekhov, A. N. (1991). Three-dimensional cytoarchitecture of normal and atherosclerotic intima of human aorta. American Journal of Pathology, 138(3), 569-580.

[33] Orekhov, A. N., Andreeva, E. R., Krushinsky, A. V., \& Smirnov, V. N. (1984). Primary cultures of enzyme-isolated cells from normal and atherosclerotic human aorta. Medical Biology, 62(4), 255-259.

[34] Orekhov, A. N., Tertov, V. V., Novikov, I. D., Krushinsky, A. V., Andreeva, E. R., Lankin, V. Z., \& Smirnov, V. N. (1985). Lipids in cells of atherosclerotic and uninvolved human aorta. I. Lipid composition of aortic tissue and enzyme isolated and cultured cells. Experimental and Molecular Pathology, 42(1), 117-137.

[35] Orekhov, A. N., Krushinsky, A. V., Andreeva, E. R., Repin, V. S., \& Smirnov, V. N. (1986). Adult human aortic cells in primary culture: heterogeneity in shape. Heart and Vessels, 2(4), 193-201.

[36] Smirnov, V. N., \& Orekhov, A. N. (1990). Smooth muscle cells from adult human aorta. In: Piper H.M. (ed). Cell Culture Techniques in Heart and Vessel Research. Berlin, Heidelberg, New York, London, Paris, Tokyo, Hong Kong: Springer-Verlag, 271-289.

[37] Yamada, S., Guo, X., Yoshizawa, M., Li, Z., Matsuyama, A., Hashimoto, H., \& Sasaguri, Y. (2011). Primary desmoplastic cutaneous leiomyosarcoma associated with high MIB-1 labeling index: a teaching case giving rise to diagnostic difficulties on a small biopsy specimen. Pathology, Research and Practice, 207(11), 728-732.

[38] Orekhov, A. N., Kosykh, V. A., Repin, V. S., \& Smirnov, V. N. (1983). Cell proliferation in normal and atherosclerotic human aorta. II. Autoradiographic observation on deoxyribonucleic acid synthesis in primary cell culture. Laboratory Investigation, 48(6), 749-754.

[39] Orekhov, A. N., Tertov, V. V., Kudryashov, S. A., Khashimov, Kh. A., \& Smirnov, V. N. (1986). Primary culture of human aortic intima cells as a model for testing antiatherosclerotic drugs. Effects of cyclic AMP, prostaglandins, calcium antagonists, antioxidants, and lipid-lowering agents. Atherosclerosis, 60(2), 101-110.

[40] Chazov, E. I., Repin, V. S., Orekhov, A. N., Antonov, A. S., Preobrazhensky, S. N., Soboleva, E. L., \& Smirnov, V. N. (1987). Atherosclerosis: what has been learned studying human arteries. Atherosclerosis Reviews, 14, 7-60. 
[41] Orekhov, A. N., Tertov, V. V., Kudryashov, S. A., \& Smirnov, V. N. (1990). Triggerlike stimulation of cholesterol accumulation and DNA and extracellular matrix synthesis induced by atherogenic serum or low density lipoprotein in cultured cells. Circulation Research, 66(2), 311-320.

[42] Tertov, V. V., Orekhov, A. N., Repin, V. S., \& Smirnov, V. N. (1982). Dibutyryl cyclic AMP decrease proliferative activity and the cholesteryl ester content in cultured cells of atherosclerotic human aorta. Biochemical and Biophysical Research Communications, 109(4), 1228-1233.

[43] Tertov, V. V., Orekhov, A. N., \& Smirnov, V. N. (1986). Effect of cyclic AMP on lipid accumulation and metabolism in human atherosclerotic aortic cells. Atherosclerosis, 62(1), 55-64.

[44] Tertov, V. V., Orekhov, A. N., \& Smirnov, V. N. (1986). Agents that increase cellular cyclic AMP inhibit proliferative activity and decrease lipid content in cells cultured from atherosclerotic human aorta. Artery, 13(6), 365-372.

[45] Tertov, V. V., Orekhov, A. N., Kudryashov, S. A., Klibanov, A. L., Ivanov, N. N., Torchilin, V. P., \& Smirnov, V. N. (1987). Cyclic nucleotides and atherosclerosis: studies in primary culture of human aortic cells. Experimental and Molecular Patholology, 47(3), 377-389.

[46] Kudryashov, S. A., Tertov, V. V., Orekhov, A. N., Geling, N. G., \& Smirnov, V. N. (1984). Regression of atherosclerotic manifestations in primary culture of human aortic cells: effects of prostaglandins. Biomedica Biochimica Acta, 43(8), S284-S286.

[47] Orekhov, A. N., Tertov, V. V., \& Smirnov, V. N. (1983). Prostacyclin analogues as anti-atherosclerotic drugs. Lancet, 2(8348), 521.

[48] Orekhov, A. N., Tertov, V. V., Mazurov, A. V., Andreeva, E. R., Repin, V. S., \& Smirnov, V. N. (1986). Regression" of atherosclerosis in cell culture: effects of stable prostacyclin analogues. Drug Development Research, 9(3), 189-201.

[49] Baldenkov, G. N., Akopov, S. E., Li, H. R., \& Orekhov, A. N. (1988). Prostacyclin, thromboxane A2 and calcium antagonists: effects on atherosclerotic characteristics of vascular cells. Biomedica Biochimica Acta, 47(10-11), S324-S327.

[50] Akopov, S. E., Orekhov, A. N., Tertov, V. V., Khashimov, K. A., Gabrielyan, E. S., \& Smirnov, V. N. (1988). Stable analogues of prostacyclin and thromboxane A2 display contradictory influences on atherosclerotic properties of cells cultured from human aorta. The effect of calcium antagonists. Atherosclerosis, 72(2-3), 245-248.

[51] Tertov, V. V., Panosyan, A. G., Akopov, S. E., \& Orekhov, A. N. (1988). The effects of eicozanoids and lipoxygenase inhibitors on the lipid metabolism of aortic cells. Biomedica Biochimica Acta, 47(10-11), S286-S288.

[52] Orekhov, A. N., Misharin, A. Yu, Tertov, V. V., Khashimov, Kh. A., Pokrovsky, S. N., Repin, V. S., \& Smirnov, V. N. (1984). Artificial HDL as an anti-atherosclerotic drug. Lancet, 2(8412), 1149-1150. 
[53] Orekhov, A. N., Tertov, V. V., Khashimov, Kh. A., Kudryashov, S. A., \& Smirnov, V. N. (1986). Antiatherosclerotic effects of verapamil in primary culture of human aortic intimal cells. Journal of Hypertension, 4(4), S153-S155.

[54] Orekhov, A. N., Tertov, V. V., Khashimov, Kh. A., Kudryashov, S. A., \& Smirnov, V. N. (1987). Evidence of anti-atherosclerotic action of verapamil from direct effects on arterial cells. American Journal of Cardiology, 59(5), 495-496.

[55] Orekhov, A. N., Baldenkov, G. N., Tertov, V. V., Li, Hwa., Ryong, Kozlov. S. G., Lyakishev, A. A., Tkachuk, V. A., Ruda, M., \& Ya, Smirnov. V. N. (1988). Cardiovascular drugs and atherosclerosis: effects of calcium antagonists, beta-blockers, and nitrates on atherosclerotic characteristics of human aortic cells. Journal of Cardiovascular Pharmacology, 12(6), S66-S68.

[56] Orekhov, A. N., Baldenkov, G. N., Tertov, V. V., Ruda, M. Ya, Khashimov, Kh A., Kudryashov, S. A., Li, H. R., Kozlov, S. G., Lyakishev, A. A., Tkachuk, V. A., \& Smirnov, V. N. (1990). Anti-atherosclerotic effects of calcium antagonists. Study in human aortic cell culture. Herz, 15(2), 139-145.

[57] Giessler, Ch., Fahr, A., Tertov, V. V., Kudryashov, S. A., Orekhov, A. N., Smirnov, V. N., \& Mest-J, H. (1987). Trapidil derivatives as potential anti-atherosclerotic drugs. Arzneimittelforschung, 37(5), 538-541.

[58] Heinroth-Hoffmann, I., Kruger, J., Tertov, V. V., Orekhov, A. N., \& Mest-J, H. (1990). Influence of trapidil and trapidil derivatives on the content of cyclic nucleotides in human intima cells cultured from atherosclerotic plaques. Drug Development Research, 19(3), 321-327.

[59] Li, H. R., Tertov, V. V., Vasil'ev, A. V., Tutel'yan, V. A., \& Orekhov, A. N. (1989). Anti-atherogenic and anti-atherosclerotic effects of mushroom extracts revealed in human aortic intima cell culture. Drug Development Research, 17(1), 109-117.

[60] Orekhov, A. N., Ruda, M. Ya, Baldenkov, G. N., Tertov, V. V., Khashimov, Kh. A., Li, H. R., Lyakishev, A. A., Kozlov, S. G., Tkachuk, V. A., \& Smirnov, V. N. (1988). Atherogenic effects of beta blockers on cells cultured from normal and atherosclerotic aorta. American Journal of Cardiology, 61(13), 1116-1117.

[61] Chazov, E. I., Tertov, V. V., Orekhov, A. N., Lyakishev, A. A., Perova, N. V., Kurdanov, Kh. A., Khashimov, Kh. A., Novikov, I. D., \& Smirnov, V. N. (1986). Atherogenicity of blood serum from patients with coronary heart disease. Lancet, 2(8507), 595-598.

[62] Tertov, V. V., Orekhov, A. N., Li, Hwa., \& Ryong, Smirnov. V. N. (1988). Intracellular cholesterol accumulation is accompanied by enhanced proliferative activity of human aortic intimal cells. Tissue and Cell, 20(6), 849-854.

[63] Orekhov, A. N., Tertov, V. V., Pokrovsky, S. N., Adamova, I., Yu, , Martsenyuk, O. N., Lyakishev, A. A., \& Smirnov, V. N. (1988). Blood serum atherogenicity associated with coronary atherosclerosis. Evidence for nonlipid factor providing atherogenicity 
of low-density lipoproteins and an approach to its elimination. Circulation Research, 62(3), 421-429.

[64] Tertov, V. V., Orekhov, A. N., Martsenyuk, O. N., Perova, N. V., \& Smirnov, V. N. (1989). Low density lipoproteins isolated from the blood of patients with coronary heart disease induce the accumulation of lipids in human aortic cells. Experimental and Molecular Pathology, 50(3), 337-347.

[65] Orekhov, A. N. (1990). In vitro models of anti-atherosclerotic effects of cardiovascular drugs. American Journal of Cardiology, 66(21), 231-281.

[66] Palatini, P. (2009). Elevated heart rate in cardiovascular diseases: a target for treatment? Progress in cardiovascular diseases, 52(1), 46-60.

[67] Schulman, I. H., Zachariah, M., \& Raij, L. (2005). Calcium channel blockers, endothelial dysfunction, and combination therapy. Aging Clinical and Experimental Research, (4), 40-5.

[68] Loaldi, A., Polese, A., Montorsi, P., De Cesare, N., Fabbiocchi, F., Ravagnani, P., \& Guazzi, MD. (1989). Comparison of nifedipine, propranolol and isosorbide dinitrate on angiographic progression and regression of coronary arterial narrowings in angina pectoris. American Journal of Cardiology, 64(8), 433-439.

[69] Fei, W., Tong, T., Yifeng, P., Jingli, T., Weizhong, G., Guangyu, T., Daoying, G., \& Yingsheng, C. (2011). A modified rabbit model of carotid atherosclerotic plaque suitable for the stroke study and MRI evaluation. International Journal of Neuroscience, 121(12), 662-669.

[70] Lavu, M., Bhushan, S., \& Lefer, D. J. (2011). Hydrogen sulfide-mediated cardioprotection: mechanisms and therapeutic potential. Clinical ScienceLondon); , 120(6), 219-229.

[71] Prasad, K. (2010). Natural products in regression and slowing of progression of atherosclerosis. Current Pharmaceutical Biotechnology, 11(8), 794-800.

[72] El -Sayyad, H. I., Abou-Naga El, A. M., Gadallah, A. A., \& Bakr, I. H. (2010). Protective effects of Allium sativum against defects of hypercholesterolemia on pregnant rats and their offspring. International Journal of Clinical and Experimental Medicine, 3(2), 152-163.

[73] Lei, Y. P., Liu, C. T., Sheen, L. Y., Chen, H. W., \& Lii, C. K. (2010). Diallyl disulfide and diallyl trisulfide protect endothelial nitric oxide synthase against damage by oxidized low-density lipoprotein. Molecular Nutrition \& Food Research, 54(1), S42-S52.

[74] Reinhart, K. M., Talati, R., White, C. M., \& Coleman, C. I. (2009). The impact of garlic on lipid parameters: a systematic review and meta-analysis. Nutrition Research Reviews, 22(1), 39-48.

[75] Chen, Z. Y., Jiao, R., \& Ma, K. Y. (2008). Cholesterol-lowering nutraceuticals and functional foods. Journal of Agricultural and Food Chemistry, 56(19), 8761-8773. 
[76] Vidyashankar, S., Sambaiah, K., \& Srinivasan, K. (2010). Regression of preestablished cholesterol gallstones by dietary garlic and onion in experimental mice. Metabolism, 59(10), 1402-1412.

[77] Simon, A., Giral, P., \& Levenson, J. (1995). Extracoronary atherosclerotic plaque at multiple sites and total coronary calcification deposit in asymptomatic men. Association with coronary risk profile. Circulation, 92(6), 1414-1421.

[78] Mitchell, J. R., \& Schwartz, C. J. (1962). Relationship between arterial disease at different sites. British Medical Journal, 1(5288), 1293-1301.

[79] Craven, T. E., Ryu, J. E., Espeland, M. A., Kahl, F. R., Mc Kinney, W. M., Toole, J. F., Mc Mahan, M. R., Thompson, C. J., Heiss, G., \& Crouse, J. R. 3rd. (1990). Evaluation of the associations between carotid artery atherosclerosis and coronary artery stenosis. A case-control study. Circulation, 82(4), 1230-1242.

[80] Geroulakos, G., O'Gorman, D. J., Kalodiki, E., Sheridan, D. J., \& Nicolaides, A. N. (1994). The carotid intima-media thickness as a marker of the presence of severe symptomatic coronary artery disease. European Heart Journal, 15(6), 781-785.

[81] Geroulakos, G., O'Gorman, D., Nicolaides, A., Sheridan, D., Elkeles, R., \& Shaper, A. G. (1994). Carotid intima-media thickness: correlation with the British Regional Heart Study risk score. Journal of Internal Medicine, 235(5), 431-433.

[82] Crouse, J. R. 3rd, Craven, T. E., Hagaman, A. P., \& Bond, M. G. (1995). Association of coronary disease with segment-specific intimal-medial thickening of the extracranial carotid artery. Circulation, 92(5), 1141-1147.

[83] Blankenhorn, D. H., \& Hodis, H. N. (1994). George Lyman Duff Memorial Lecture. Arterial imaging and atherosclerosis reversal. Arteriosclerosis and Thrombosis, 14(2), 177-192.

[84] Hodis, H. N., Mack, W. J., La Bree, L., Selzer, R. H., Liu, C. R., Liu, C. H., \& Azen, S. P. (1998). The role of carotid arterial intima-media thickness in predicting clinical coronary events. Annals of Internal Medicine, 128(4), 262-269.

[85] Salonen, J. T., \& Salonen, R. (1993). Ultrasound B-mode imaging in observational studies of atherosclerotic progression. Circulation [3], II56-II65.

[86] Chambless, L. E., Heiss, G., Folsom, A. R., Rosamond, W., Szklo, M., Sharrett, A. R., \& Clegg, L. X. (1997). Association of coronary heart disease incidence with carotid arterial wall thickness and major risk factors: the Atherosclerosis Risk in Communities (ARIC) Study, 1987-1993. American Journal of Epidemiology, 146(6), 483-494.

[87] Bots, M. L., Hoes, A. W., Koudstaal, P. J., Hofman, A., \& Grobbee, D. E. (1997). Common carotid intima-media thickness and risk of stroke and myocardial infarction: the Rotterdam Study. Circulation, 96(5), 1432-1437.

[88] O'Leary, D. H., Polak, J. F., Kronmal, R. A., Manolio, T. A., Burke, G. L., \& Wolfson, S. K. Jr. (1999). Carotid-artery intima and media thickness as a risk factor for myocar- 
dial infarction and stroke in older adults. Cardiovascular Health Study Collaborative Research Group. New England Journal of Medicine, 340(1), 14-22.

[89] Koscielny, J., Klüssendorf, D., Latza, R., Schmitt, R., Radtke, H., Siegel, G., \& Kiesewetter, H. (1999). The antiatherosclerotic effect of Allium sativum. Atherosclerosis, 144(1), 237-249.

[90] Salonen, R., Nyyssonen, K., Porkkala, E., Rummukainen, J., Belder, R., Park, J. S., \& Salonen, J. T. (1995). Kuopio Atherosclerosis Prevention Study (KAPS). A population-based primary preventive trial of the effect of LDL lowering on atherosclerotic progression in carotid and femoral arteries. Circulation, 92(7), 1758-1764.

[91] Crouse, J. R. 3rd, Byington, R. P., Bond, M. G., Espeland, M. A., Craven, T. E., Sprinkle, J. W., Mc Govern, M. E., \& Furberg, C. D. (1995). Pravastatin, Lipids, and Atherosclerosis in the Carotid Arteries (PLAC-II). American Journal of Cardiology, 75(7), 455-459.

[92] Smilde, T. J., van Wissen, S., Wollersheim, H., Trip, MD, Kastelein, J. J., \& Stalenhoef, A. F. (2001). Effect of aggressive versus conventional lipid lowering on atherosclerosis progression in familial hypercholesterolaemia (ASAP): a prospective, randomised, double-blind trial. Lancet, 357(9256), 577-581.

[93] Pitt, B., Byington, R. P., Furberg, C. D., Hunninghake, D. B., Mancini, G. B., Miller, ME, \& Riley, W. (2000). Effect of amlodipine on the progression of atherosclerosis and the occurrence of clinical events. PREVENT Investigators. Circulation, 102(13), 1503-1510.

[94] Hodis, H. N. (1995). Reversibility of atherosclerosis--evolving perspectives from two arterial imaging clinical trials: the cholesterol lowering atherosclerosis regression study and the monitored atherosclerosis regression study. Journal of Cardiovascular Pharmacology, 25(4), S25-S31.

[95] Blankenhorn, D. H., Selzer, R. H., Crawford, D. W., Barth, JD, Liu, C. R., Liu, C. H., Mack, W. J., \& Alaupovic, P. (1993). Beneficial effects of colestipol-niacin therapy on the common carotid artery. Two- and four-year reduction of intima-media thickness measured by ultrasound. Circulation, 88(1), 20-28.

[96] Blankenhorn, D. H., Azen, S. P., Kramsch, D. M., Mack, W. J., Cashin-Hemphill, L., Hodis, H. N., De Boer, L. W., Mahrer, P. R., Masteller, MJ, Vailas, L. I., Alaupovic, P., Hirsch, L. J. M. A. R. S., \& Research, Group. (1993). Coronary angiographic changes with lovastatin therapy. The Monitored Atherosclerosis Regression Study (MARS). The MARS Research Group. Annals of Internal Medicine, 119(10), 969-976.

[97] Zanchetti, A., Rosei, E. A., Dal, Palù. C., Leonetti, G., Magnani, B., \& Pessina, A. (1998). The Verapamil in Hypertension and Atherosclerosis Study (VHAS): results of long-term randomized treatment with either verapamil or chlorthalidone on carotid intima-media thickness. Journal of Hypertension, 16(11), 1667-1676. 
[98] Orekhov, A. N., \& Tertov, V. V. (1997). In vitro effect of garlic powder extract on lipid content in normal and atherosclerotic human aortic cells. Lipids, 32(10), 1055-1060.

[99] Orekhov, A. N., Tertov, V. V., Sobenin, I. A., \& Pivovarova, E. M. (1995). Direct antiatherosclerosis-related effects of garlic. Annals of Medicine, 27(1), 63-65.

[100] Campbell, J. H., Efendy, J. L., Smith, N. J., \& Campbell, G. R. (2001). Molecular basis by which garlic suppresses atherosclerosis. The Journal of Nutrition, 131(3e), 1006S-1009S.

[101] Block, E. (1985). The chemistry of garlic and onions. Scientific American, 252(3), 114-119.

[102] Iberl, B., Winkler, G., Müller, B., \& Knobloch, K. (1990). Quantitative determination of allicin and alliin from garlic by HPLC. Planta Medica, 56(3), 320-326.

[103] Amagase, H., Petesch, B. L., Matsuura, H., Kasuga, S., \& Itakura, Y. (2001). Intake of garlic and its bioactive components. The Journal of Nutrition, 131(3s), 955S-62S.

[104] Siasos, G., Tousoulis, D., Kioufis, S., Oikonomou, E., Siasou, Z., Limperi, M., Papavassiliou, A. G., \& Stefanadis, C. (2012). Inflammatory mechanisms in atherosclerosis: the impact of matrix metalloproteinases. Current Topics in Medicinal Chemistry, 12(10), $1132-1148$.

[105] Bona, R. D., Liuzzo, G., Pedicino, D., \& Crea, F. (2011). Anti-inflammatory treatment of acutecoronary syndromes. Current Pharmaceutical Design, 17(37), 4172-4189.

[106] Weber, C., \& Noels, H. (2011). Atherosclerosis: current pathogenesis and therapeutic options. Nature Medicine, 17(11), 1410-1422.

[107] Koenen, R. R., \& Weber, C. (2011). Chemokines: established and novel targets in atherosclerosis. EMBO Molecular Medicine, 3(12), 713-725.

[108] Burger, H. G., Maclennan, A. H., Huang, K. E., \& Castelo-Branco, C. (2012). Evidence-based assessment of the impact of the WHI on women's health. Climacteric, 15, 281-287.

[109] de Villiers, T. J., \& Stevenson, J. C. (2012). The WHI. the effect of hormone replacement therapy on fracture prevention. Climacteric, 15(3), 263-266.

[110] Ellis, M. J., Suman, V. J., Hoog, J., Lin, L., Snider, J., Prat, A., Parker, J. S., Luo, J., De Schryver, K., Allred, D. C., Esserman, L. J., Unzeitig, G. W., Margenthaler, J., Babiera, G. V., Marcom, P. K., Guenther, J. M., Watson, M. A., Leitch, M., Hunt, K., \& Olson, J. A. (2011). Randomized phase II neoadjuvant comparison between letrozole, anastrozole, and exemestane for postmenopausal women with estrogen receptor-rich stage 2 to 3 breast cancer: clinical and biomarker outcomes and predictive value of the baseline PAM50-based intrinsic subtype--ACOSOG Z1031. Journal of Clinical Oncology, 29(17), 2342-2349.

[111] Smith, N. L., Wiley, J. R., Legault, C., Rice, K. M., Heckbert, S. R., Psaty, Tracy. R. P., \& Cushman, M. (2008). Effect of progestogen and progestogen type on hemostasis 
measures in postmenopausal women: the Postmenopausal Estrogen/Progestin Intervention (PEPI) Study. Menopause, 15(6), 1145-1150.

[112] Masood, D. E., Roach, E. C., Beauregard, K. G., \& Khalil, R. A. (2010). Impact of sex hormone metabolism on the vascular effects of menopausal hormone therapy in cardiovascular disease. Current Drug Metabolism, 11(8), 693-714.

[113] Pellegrini, C. N., Vittinghoff, E., Lin, F., Hulley, S. B., \& Marcus, G. M. (2009). Statin use is associated with lower risk of atrial fibrillation in women with coronary disease: the HERS trial. Heart, 95(9), 704-708.

[114] Gorchakova, T. V., Suprun, I. V., Sobenin, I. A., \& Orekhov, A. N. (2007). Use of natural products in anticytokine therapy. Bulletin of Experimental Biology and Medicine, 143(3), 316-319.

[115] Nikitina, N. A., Sobenin, I. A., Myasoedova, V. A., Korennaya, V. V., Mel'nichenko, A. A., Khalilov, E. M., \& Orekhov, A. N. (2006). Antiatherogenic effect of grape flavonoids in an ex vivo model. Bulletin of Experimental Biology and Medicine, 141(6), 712-725.

[116] Orekhov, A. N., Tertov, V. V., \& Pivovarova, E. M. (1998). The effects of antihypertensive agents on atherosclerosis-related parameters of human aorta intimal cells. Cardiology, 89(2), 111-118.

[117] Sobenin, I. A., Maksumova, M. A., Slavina, E. S., Balabolkin, M. I., \& Orekhov, A. N. (1994). Sulfonylurea sinduce cholesterol accumulation in cultured human intimal cells and macrophages. Atherosclerosis, 105(2), 159-163. 
